\title{
Analyzing thermoregulation processes in early school-age girls and boys through thermography
}

\author{
Agnieszka Dębiec-Bąk ${ }^{1} \cdot$ Tomasz Kuligowski $^{1}$ (D) - Anna Skrzek ${ }^{1}$
}

Received: 14 April 2019/Accepted: 15 September 2019/Published online: 25 September 2019

(C) The Author(s) 2019

\begin{abstract}
The research assessed thermoregulation processes in early school-age children. Thermal maps of the subjects' bodies were compared before and after general physical exercise and after post-exercise restitution to establish differences between the sexes. The research involved 40 students aged 7 , including 20 boys. The subjects participated in interval training which maintained the pulse at 60-80\% HRmax. Measurements of body surface temperatures were taken in 12 fields with ThermoVision FLIR SYSTEM T335 camera before exercise, immediately after exercise and after 15 min of restitution. Statistical analysis was based on the Shapiro-Wilk test to verify the normality of variables, multivariate analysis of variance, Student's $t$ test for independent samples and Duncan's post hoc test. The level of statistical significance was established at $p<0.05$. Analysis of the results showed a difference in the distribution of surface body temperatures in boys and girls depending on the studied area. The highest values were recorded in the trunk area, and the lowest in the lowerlimb area. Statistical analysis demonstrated that in both groups there was a statistically significant decrease in post-exercise temperatures. The results revealed greater efficiency of thermoregulation processes during restitution in girls, because the values obtained in all measurement fields in Test 3 were higher than the pre-exercise values. In Tests 2 and 3 , differences between the sexes were reported mainly in the upper-limb area.
\end{abstract}

Keywords Thermoregulation · Thermogenesis · Children · Thermography · Training

\section{Introduction}

Regular physical activity is crucial in adolescence because it brings numerous health benefits. If it is insufficient, it may cause irregularities in motor organs, obesity, type 2 diabetes and increased susceptibility to infection. Any deviations in the musculoskeletal system are typically corrected by kinesiotherapy in the form of therapeutic exercises. During the exercises, metabolic changes occur in the locomotor system and thermoregulation processes are activated, whose aim is to decrease the body temperature of the exerciser to enable the continuation of physical activity without hazard to the body. Changes reflected by the emissivity of surface body temperature provide

Tomasz Kuligowski

tomasz.kuligowski@awf.wroc.pl

1 Department of Physiotherapy in Motor Organ Dysfunctions, Faculty of Physiotherapy, University School of Physical Education in Wrocław, Wrocław, Poland information about temperature variations and achieving post-workout homeostasis of the body [1].

The human body strives to maintain equilibrium regardless of the surrounding environment. This process is known as homeostasis. In order to maintain physiological thermal balance, a number of factors conditioning its proper functioning are activated. Man is a homeotherm, i.e., an organism that maintains constant body core temperature of about $36.7^{\circ} \mathrm{C}$, and its fluctuations are estimated at $0.6{ }^{\circ} \mathrm{C}$ [2]. The body temperature is conditioned by two opposite processes - the removal of heat and its production. An important role is played by thermoregulation, which is defined as the ability to maintain a relatively constant body temperature. The main source of heat is the metabolism of the human body, which is determined by basal metabolic rate, the work of skeletal muscles and of hormones thyroxine, adrenaline and noradrenaline, and specific dynamic action of food. Most of the heat is generated in the internal organs, particularly the liver, brain and skeletal muscles during physical activity [3]. 
Among the processes responsible for removing heat, and consequently reducing the body temperature, are evaporation, conduction, convection and radiation [4]. Thermoregulation mechanisms differ with respect to the percentage of heat removal, depending on whether the body is currently at rest or performing physical activity. While at rest, $60 \%$ of heat is removed through radiation, whereas during physical exertion $80 \%$ of heat is removed through sweat evaporation [5].

Maintaining the proper thermal equilibrium is also affected by the efficiency of chemical thermoregulation. It is based on the ratio of calcium and sodium ions in the posterior hypothalamus. When the amount of sodium ions increases, processes preventing heat loss and stimulating its production are triggered, which result in a higher body temperature. However, increasing the concentration of calcium ions leads to a decrease in body temperature [6].

Depending on which part of the thermoregulatory center is stimulated, feedback processes will begin to lower or increase the body temperature. The anterior hypothalamus is responsible for triggering heat removal mechanisms, whereas its posterior part stimulates heat production and maintenance. Sweat glands also serve an important function because evaporation accounts for significant heat losses [2].

During physical activity, metabolic processes are intensified in order to provide the energy necessary for muscle contraction. These processes result in increased human body temperature. The temperature of relaxed muscles oscillates between 34 and $36^{\circ} \mathrm{C}$, but during moderate training it grows by several degrees in a few minutes. The produced heat is transferred to the blood, and through the circulatory system, it spreads to the entire body. Importantly, during prolonged physical effort, the body temperature does not rise throughout it. After about $30 \mathrm{~min}$, it reaches a level that is maintained until physical exertion finishes. In order to remove excess heat from the surface of the skin, evaporation processes intensify to enable prolonged muscle work. The thermoregulatory response during physical exercise depends on external conditions, body hydration, blood volume, ion concentration in body fluids and physical fitness [7].

Physical activity in a hot environment leads to blood distribution imbalance. The body of an adult person directs part of the blood to the skin, which results from the stimulation of the thermoregulation system, thus reducing the amount transported to the muscles. Venous return is also reduced, thereby lowering the heart's ejection fraction. These changes lead to an accelerated heart rate, which ensures a constant level of cardiac output per minute. A child's body is characterized by worse thermoregulation in high external temperatures. The processes of heat removal through evaporation are less efficient, and the time of thermal adjustment is longer than in the case of an adult $[3,8]$.

Physical capacity is subject to significant fluctuations in ontogeny. It is conditioned by many factors, including energy transformation, efficient functioning of the nervous and muscular systems, body size, fluid and electrolyte balance and thermoregulation [9]. Children's physical capacity is lower due to the ongoing maturation processes and the development of the muscular, cardiovascular and nervous systems. Boys' muscle mass during puberty is higher compared to girls due to the production of androgen. The secretion of estrogens in females increases the amount of subcutaneous fat. As age increases, so does the degree of myelination of nerve fibers, the ejection fraction of the heart, the maximum cardiac output per minute and all lung ventilation volumes [10].

The efficiency of the thermoregulation system changes in ontogeny. With age, the human body is characterized by different adaptability and efficiency levels of thermoregulation processes. Dimorphic differences in the thermoregulatory reaction of the body begin to appear in adolescence. An analysis of these changes by means of thermography can provide information about how quickly the body returns to thermal homeostasis after physical exertion by mapping body heat production in the wake of physical exertion. Thermography can also be used in the prevention of injuries and controlling the progression of motor features [11, 12].

The aim of this research was to assess thermoregulation processes in girls and boys in early school age by means of thermographic analysis of surface temperatures in various areas of the body. A comparison of body heat maps of the subjects before and after general physical exercise and after post-exercise restitution was made for both sexes.

\section{Methods}

\section{Subjects}

The study included 40 schoolchildren at the age of 7 attending Primary School number 9 in Opole. The group consisted of 20 boys with a mean body mass of $25.8 \mathrm{~kg}$ $( \pm 3.19)$ and an average height of $126.5 \mathrm{~cm}( \pm 5.81)$ and 20 girls with a mean body mass of $24.6 \mathrm{~kg}( \pm 3.06)$ and average height of $123.2 \mathrm{~cm}( \pm 4.46)$.

The research was approved by the Senate Committee on Ethics of Scientific Research at the University School of Physical Education (28 June 2007). Informed consent was obtained from all individual participants included in the study. The authors of the research obtained consent from the persons examined with the probe to participate in the research. 
The criteria for including the subjects in the research were:

- good health confirmed by the current medical examination of the child (performed by the school nurse and a local primary care health center),

- permission of the head of school to conduct the research,

- consent of parents or legal guardians of the subjects to participate in the research.

The criteria for excluding from the research were a child's ill health or exemption from physical education classes.

\section{Research methods}

Surface body temperatures were recorded using the FLIR SYSTEM T335 thermal imaging camera. The measurements were taken in the physical education teacher's office in the 1:1 system. (Only the researcher and the subject were present in the room.) The research consisted of taking three pictures of the child without outerwear, from the front and back, standing in the standard anatomical position at a distance of 2 meters from the camera. After the first thermogram (Test 1), the children took part in a unit of physical exercise.

Training followed a pattern of general physical exercises which maintained the pulse at 60-80\% HRmax. Heart rate values were measured using Polar FT7 heart rate monitors. The training protocol was similar to the exercise model included in the Functional Movement Screen (FMS) training.

After the end of the exercise, Test 2 was performed, and then after 15 min of restitution, the third thermal image was taken (Test 3).

The subjects had been informed about the test protocol and the proper behavior during the thermal imaging process. The obtained curves were analyzed using the ThermaCAM Researcher 2.10 Pro program, by means of which 12 measurement fields were marked out on the body of the subjects, from the front and back, in a standing position (Figs. 1, 2). Fields A1, A2, A7, A8 show temperature changes in the trunk area, fields A3, A4, A9, A10 represent the area of upper limbs, and fields A5, A6, A11, A12 cover the lower limbs.

\section{Training unit protocol}

The study was based on physical activities similar to the fundamental movement patterns in the FMS training. However, the training unit performed by the subjects was a

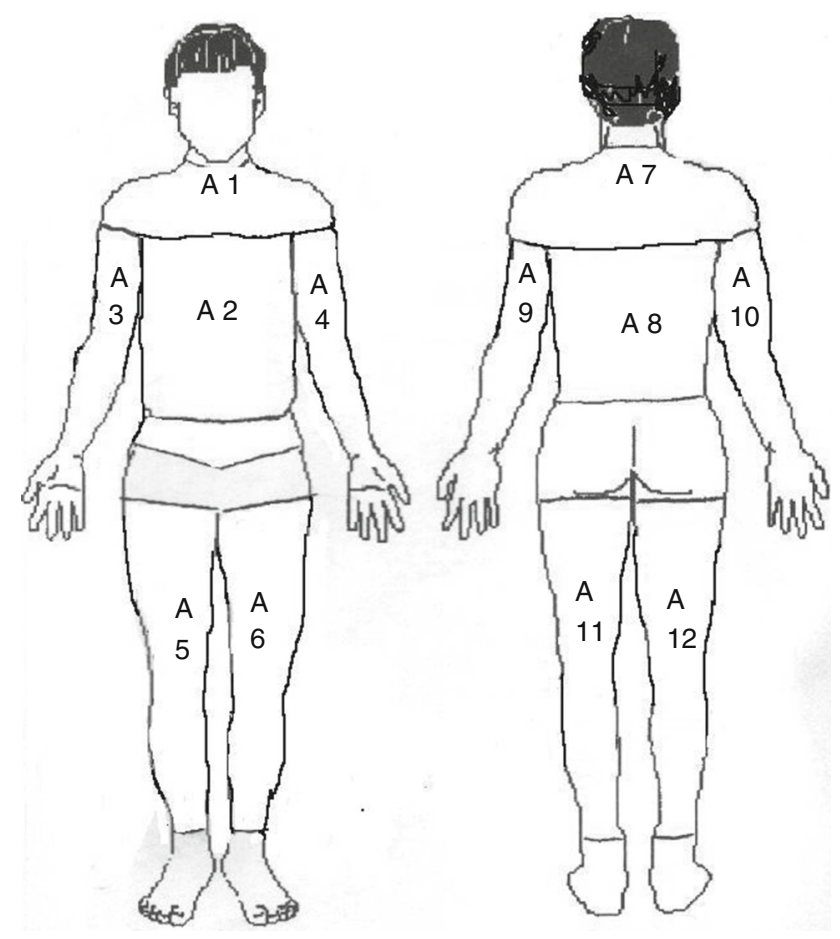

Fig. 1 Measurement fields in 12 body areas

modification of the seven fundamental movement patterns of the FMS. The exercises were preceded by a warm-up consisting of marching on the spot, trotting and exercises activating the shoulder and hip joints in all planes of mobility. The duration of the initial part of the exercise was 10 min. Next, the main part of the training with progressive effort was used, which consisted of a modification of the seven fundamental movement patterns tests of the FMS. Its duration was $30 \mathrm{~min}$.

Each movement pattern was repeated ten times:

- shoulder girdle exercises in all planes and with a load (0.5-1 kg) above the head (overhead squats): they improve central stability, stability of shoulder joints and upper-limb strength,

- dumbbell overhead squats, squat jumps, squats with a cane in front or on the shoulders: they activate the gluteal muscles, biceps, quadriceps femoris, muscles of the torso,

- single-leg squats: they develop leg strength and have a strong stabilizing effect on the ankle and knee,

- split squats: they increase flexibility, balance and strength of the leg,

- stabilization exercises on stable and unstable ground (Bobath balls and mats):

- supported kneel with uplifts of opposing limbs, e.g., upper right limb-bottom left limb;

- front holds on the forearms, i.e., the so-called forearm plank; 
Fig. 2 Description of measurement areas (A1-A12)
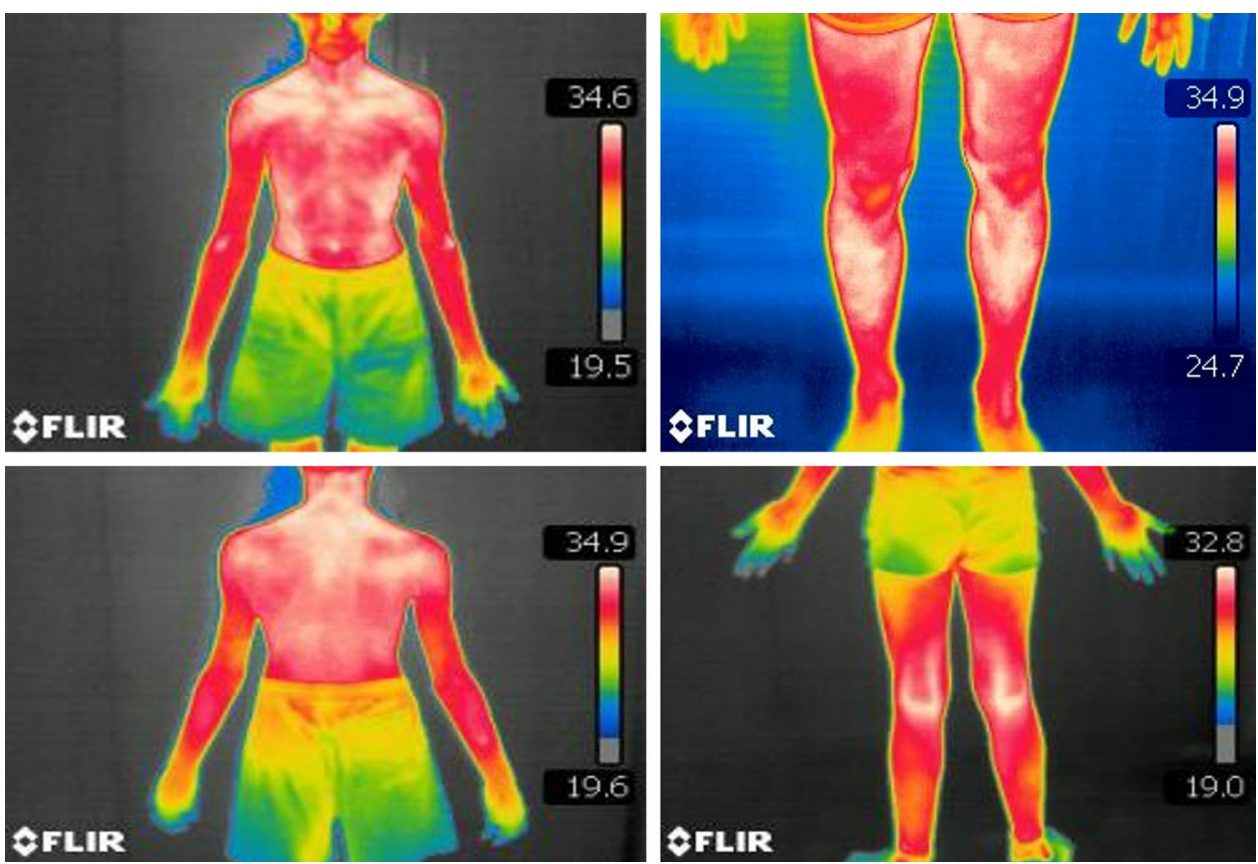

- front and back holds with the rise of one of the lower limbs;

- side plank with the rise of one of the lower limbs.

The following equipment was used to carry out the training unit: TheraBand tape with low resistance level, exercise canes, medicine and gym balls, balance soft disks, dumbbells and exercise benches.

The part of the training unit in the form of restitution after physical activity consisted of a slow march, reducing the movement amplitude until stop and breathing exercises in a standing position. Its duration was 5-7 $\mathrm{min}$.

\section{Statistical methods}

For statistical calculations, Statistica version $13.0 \mathrm{Pl}$ was used. The normality of the analyzed variables was verified by the Shapiro-Wilk test. The arithmetic mean, maximum and minimum values and standard deviation were used to analyze the selected values and describe statistical variables. To test the differences in temperatures between the sex groups, Student's $t$ test was carried out. The assessment of differences between the analyzed variables was based on the results of a multivariate analysis of variance (MANOVA) followed by the post hoc Duncan's test. All verified tests and coefficients at the level of $p<0.05$ were considered statistically significant.

\section{Results}

An analysis of average temperature values of specific body areas revealed their differentiation. The highest mean values were recorded in the rear view of the A7 field of the shoulder belt $\left(32.9^{\circ} \mathrm{C}\right)$ and the A1 frontal area $\left(32.7^{\circ} \mathrm{C}\right)$. The lowest average values were recorded in the area of the lower limbs in frontal views A5 $\left(28.5^{\circ} \mathrm{C}\right)$ and $\mathrm{A} 6$ $\left(29.3{ }^{\circ} \mathrm{C}\right)$.

The difference in mean temperatures of individual body regions in girls was lower than that in boys. The lowest and highest values oscillated between $32.5^{\circ} \mathrm{C}$ and $29.1^{\circ} \mathrm{C}$. Similarly to boys, the highest mean temperatures were measured within the shoulder belt in the A7 rear view $\left(32.5^{\circ} \mathrm{C}\right)$ and $\mathrm{A} 1$ from the front $\left(32.3^{\circ} \mathrm{C}\right)$. The lowest mean temperatures were recorded in the area of the lower limbs, A5 $\left(29.2^{\circ} \mathrm{C}\right)$ and A6 $\left(29.1^{\circ} \mathrm{C}\right)$. After statistical analysis, no statistically significant differences between the groups were found in any of the areas measured in Test 1 (Table 1).

A statistical analysis carried out with Student's $t$ test for independent samples in Test 2 showed statistically significant differences with respect to sexual dimorphism mainly in the area of upper limbs (A9, A10), in the back view of the shoulder belt (A7) and of the lower left limb (A11) (Table 2).

An analysis of the obtained results revealed that sexual dimorphism in the period of post-exercise restitution, i.e., in Test 3, manifested itself only in the upper-limb area in frontal view (Table 3), where the differences were statistically significant. 
Table 1 Temperature differentiation analysis for all measurement fields in girls and boys in Test 1 (Student's $t$ test for independent samples)
Table 2 Temperature differentiation analysis for all measurement fields in girls and boys in Test 2 (Student's $t$ test for independent samples)
Table 3 Temperature differentiation analysis for all measurement fields in girls and boys in Test 3 (Student's $t$ test for independent samples)

\begin{tabular}{|c|c|c|c|c|c|c|}
\hline Measurement field & $\begin{array}{l}\text { Average temperature } /{ }^{\circ} \mathrm{C} \\
\mathrm{M}\end{array}$ & $\begin{array}{l}\text { SD } \\
\mathrm{M}\end{array}$ & $\begin{array}{l}\text { Average temperature } /{ }^{\circ} \mathrm{C} \\
\mathrm{F}\end{array}$ & $\begin{array}{l}\text { SD } \\
\text { F }\end{array}$ & $t$ & $p$ \\
\hline A1 & 32.75 & 1.100 & 32.35 & 0.632 & 1.393 & 0.172 \\
\hline A2 & 32.34 & 1.414 & 31.87 & 0.803 & 1.279 & 0.209 \\
\hline A3 & 30.51 & 0.969 & 30.49 & 0.918 & 0.067 & 0.947 \\
\hline A4 & 30.43 & 0.963 & 30.34 & 0.729 & 0.333 & 0.741 \\
\hline A5 & 29.43 & 0.935 & 29.25 & 0.843 & 0.622 & 0.538 \\
\hline A6 & 29.31 & 1.042 & 29.12 & 0.867 & 0.610 & 0.545 \\
\hline A7 & 32.96 & 0.958 & 32.58 & 0.654 & 1.484 & 0.146 \\
\hline A8 & 32.47 & 1.139 & 32.22 & 0.734 & 0.809 & 0.424 \\
\hline A9 & 29.56 & 0.782 & 29.35 & 0.737 & 0.874 & 0.387 \\
\hline A10 & 29.49 & 0.908 & 29.28 & 0.792 & 0.780 & 0.441 \\
\hline A11 & 29.78 & 1.110 & 29.42 & 0.475 & 1.333 & 0.190 \\
\hline A12 & 29.73 & 1.147 & 29.38 & 0.532 & 1.220 & 0.230 \\
\hline
\end{tabular}

\begin{tabular}{|c|c|c|c|c|c|c|}
\hline Measurement field & $\begin{array}{l}\text { Average temperature } /{ }^{\circ} \mathrm{C} \\
\mathrm{M}\end{array}$ & $\begin{array}{l}\text { SD } \\
\mathrm{M}\end{array}$ & $\begin{array}{l}\text { Average temperature } /{ }^{\circ} \mathrm{C} \\
\mathrm{F}\end{array}$ & $\begin{array}{l}\text { SD } \\
\text { F }\end{array}$ & $t$ & $p$ \\
\hline A1 & 31.90 & 1.01 & 31.34 & 0.80 & 1.95 & 0.06 \\
\hline A2 & 31.47 & 1.01 & 30.87 & 0.87 & 1.93 & 0.06 \\
\hline A3 & 29.34 & 0.90 & 28.97 & 0.87 & 1.32 & 0.19 \\
\hline A4 & 29.25 & 0.87 & 28.76 & 0.89 & 1.77 & 0.09 \\
\hline A5 & 28.56 & 0.90 & 28.51 & 1.09 & 0.18 & 0.86 \\
\hline A6 & 28.52 & 0.86 & 28.33 & 1.05 & 0.64 & 0.52 \\
\hline A7 & 32.15 & 1.03 & 31.38 & 0.92 & 2.51 & 0.02 \\
\hline A8 & 31.41 & 1.19 & 30.78 & 1.02 & 1.81 & 0.08 \\
\hline A9 & 29.05 & 0.91 & 28.39 & 0.89 & 2.34 & 0.03 \\
\hline A10 & 28.98 & 0.90 & 28.22 & 0.95 & 2.58 & 0.01 \\
\hline A11 & 29.38 & 1.13 & 28.68 & 0.69 & 2.35 & 0.02 \\
\hline A12 & 29.19 & 1.05 & 28.73 & 0.64 & 1.68 & 0.11 \\
\hline
\end{tabular}

\begin{tabular}{|c|c|c|c|c|c|c|}
\hline Measurement field & $\begin{array}{l}\text { Average temperature } /{ }^{\circ} \mathrm{C} \\
\mathrm{M}\end{array}$ & $\begin{array}{l}\mathrm{SD} \\
\mathrm{M}\end{array}$ & $\begin{array}{l}\text { Average temperature } /{ }^{\circ} \mathrm{C} \\
\mathrm{F}\end{array}$ & $\begin{array}{l}\text { SD } \\
\mathrm{F}\end{array}$ & $t$ & $p$ \\
\hline $\mathrm{P} 1$ & 32.73 & 0.96 & 32.83 & 0.61 & -0.39 & 0.70 \\
\hline $\mathrm{P} 2$ & 32.42 & 1.19 & 32.49 & 0.67 & -0.25 & 0.81 \\
\hline P3 & 30.38 & 1.05 & 31.03 & 0.70 & -2.31 & 0.03 \\
\hline P4 & 30.29 & 1.03 & 30.87 & 0.62 & -2.14 & 0.04 \\
\hline P5 & 29.69 & 1.04 & 30.16 & 0.69 & -1.68 & 0.10 \\
\hline P6 & 29.53 & 0.98 & 30.01 & 0.58 & -1.89 & 0.07 \\
\hline P7 & 32.87 & 0.98 & 32.86 & 0.65 & 0.06 & 0.95 \\
\hline P8 & 32.31 & 1.07 & 32.46 & 0.65 & -0.54 & 0.60 \\
\hline P9 & 29.71 & 0.65 & 30.00 & 0.76 & -1.27 & 0.21 \\
\hline P10 & 29.78 & 0.77 & 29.90 & 0.65 & -0.56 & 0.58 \\
\hline P11 & 30.47 & 2.30 & 30.02 & 0.59 & 0.84 & 0.41 \\
\hline P12 & 29.89 & 1.13 & 29.97 & 0.50 & -0.29 & 0.77 \\
\hline
\end{tabular}

By analyzing the average temperature values of individual body regions, differences in response to physical effort were observed between both sex groups. To illustrate these changes, the temperature of measurement fields A1, A2, A7, A8 was averaged as a temperature in the area of the torso. The temperature of measurement fields A3, A4, 
A9, A10 was averaged and shown as the temperature representing the area of upper limbs, and the average temperature in fields A5, A6, A11, A12 referred to the lower limbs. Immediately after physical activity, temperatures in boys and girls decreased in the area of the trunk (Fig. 3), upper limbs (Fig. 4) and lower limbs (Fig. 5). The changes were greater in girls and oscillated between $0.6{ }^{\circ} \mathrm{C}$ and $1.6^{\circ} \mathrm{C}$, while in boys the biggest difference was $1.2^{\circ} \mathrm{C}$.

The differences between the analyzed variables were assessed taking into account the two groups of subjects and the three subsequent tests, based on MANOVA and post hoc Duncan's test.

In Test 2, the recorded decrease in average temperatures in the trunk area in both groups reached the level of statistical significance (Table 4). The temperature of upper and lower limbs in Test 2 also revealed statistically significant lower values than that in Test 1 (Tables 5, 6).

In Test 3, average body surface temperatures in boys in most of the analyzed areas oscillated close to the initial values. It was observed that only in the area of the lower limbs the temperature exceeded the values recorded during Test 1 in a statistically significant way (Table 3 ). On the other hand, in Test 3 surface body temperatures in girls in all the measurement fields exceeded the baseline values (Table 3). Statistically significant differences between Test 1 and Test 3 in girls were found in the area of the trunk as well as upper and lower limbs (Tables 4-6).

\section{Discussion}

The correct development of a child is influenced by many factors, including those responsible for the mental state and those connected with the physical sphere. Young people's physical capacity and fitness are subject to positive changes

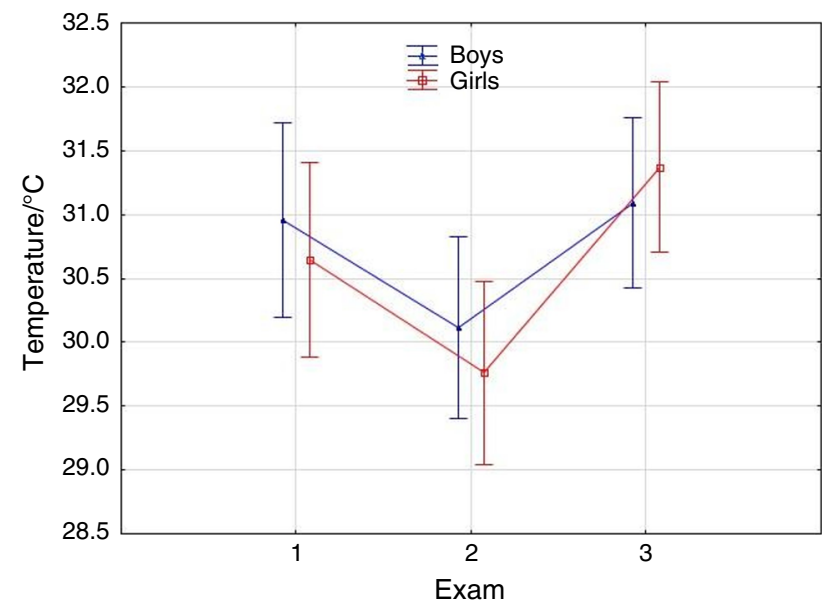

Fig. 3 Change dynamics of average body surface temperatures in both groups in the trunk area

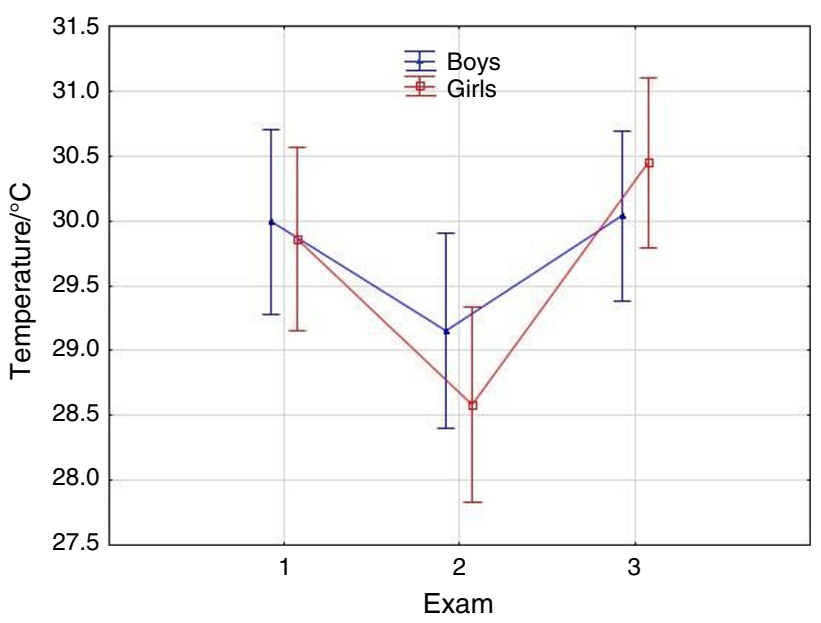

Fig. 4 Change dynamics of average body surface temperatures in both groups in the upper-limb area

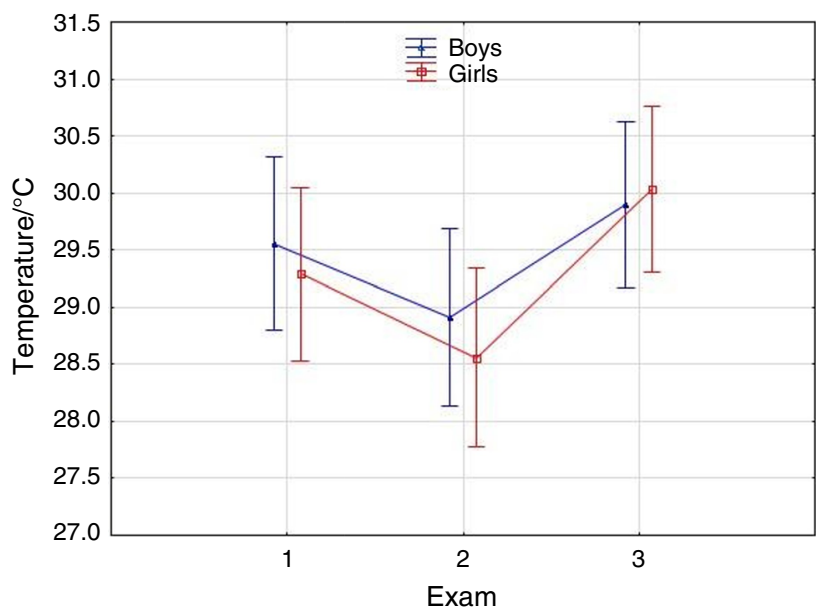

Fig. 5 Change dynamics of average body surface temperatures in both groups in the lower-limb area

Table 4 Detailed presentation of average surface temperatures of the trunk area using Duncan's test

\begin{tabular}{llllllll}
\hline Sex & Exam & 1 & 2 & 3 & 4 & 5 & 6 \\
& & 32.63 & 31.73 & 32.58 & 32.25 & 31.09 & 32.66 \\
\hline $\mathrm{M}$ & 1 & & 0.00 & 0.76 & 0.21 & 0.00 & 0.91 \\
$\mathrm{M}$ & 2 & 0.00 & & 0.00 & 0.07 & 0.03 & 0.00 \\
$\mathrm{M}$ & 3 & 0.76 & 0.00 & & 0.25 & 0.00 & 0.80 \\
$\mathrm{~F}$ & 1 & 0.21 & 0.07 & 0.25 & & 0.00 & 0.01 \\
$\mathrm{~F}$ & 2 & 0.00 & 0.03 & 0.00 & 0.00 & & 0.00 \\
$\mathrm{~F}$ & 3 & 0.91 & 0.00 & 0.80 & 0.01 & 0.00 & \\
\hline
\end{tabular}

in accordance with the principles of ontogeny. In order to assess physical capacity, biological age should be taken into account because the difference between people who are of the same chronological age may reach up to 3 years in terms of biological development. Cardiopulmonary 
Table 5 Detailed presentation of average surface temperatures of the upper-limb area using Duncan's test

\begin{tabular}{llllllll}
\hline Sex & Exam & 1 & 2 & 3 & 4 & 5 & 6 \\
& & 29.99 & 29.15 & 30.04 & 29.86 & 28.584 & 30.447 \\
\hline $\mathrm{M}$ & 1 & & 0.00 & 0.81 & 0.59 & 0.00 & 0.08 \\
$\mathrm{M}$ & 2 & 0.00 & & 0.00 & 0.00 & 0.02 & 0.00 \\
$\mathrm{M}$ & 3 & 0.81 & 0.00 & & 0.50 & 0.00 & 0.10 \\
$\mathrm{~F}$ & 1 & 0.59 & 0.01 & 0.50 & & 0.00 & 0.00 \\
$\mathrm{~F}$ & 2 & 0.00 & 0.02 & 0.00 & 0.00 & & 0.00 \\
$\mathrm{~F}$ & 3 & 0.08 & 0.00 & 0.10 & 0.00 & 0.00 & \\
\hline
\end{tabular}

Table 6 Detailed presentation of average surface temperatures of the lower-limb area using Duncan's test

\begin{tabular}{llllllll}
\hline Sex & Exam & 1 & 2 & 3 & 4 & 5 & 6 \\
& & 29.557 & 28.911 & 29.893 & 29.291 & 28.560 & 30.039 \\
\hline $\mathrm{M}$ & 1 & & 0.00 & 0.02 & 0.32 & 0.00 & 0.09 \\
$\mathrm{M}$ & 2 & 0.00 & & 0.00 & 0.16 & 0.19 & 0.00 \\
$\mathrm{M}$ & 3 & 0.02 & 0.00 & & 0.03 & 0.00 & 0.58 \\
$\mathrm{~F}$ & 1 & 0.32 & 0.16 & 0.03 & & 0.00 & 0.00 \\
$\mathrm{~F}$ & 2 & 0.00 & 0.19 & 0.00 & 0.00 & & 0.00 \\
$\mathrm{~F}$ & 3 & 0.09 & 0.00 & 0.58 & 0.00 & 0.00 & \\
\hline
\end{tabular}

parameters, muscle strength, fluid and electrolyte management, development of the central and peripheral nervous system and the efficiency of thermoregulation processes determine physical capacity. Changes in the individual systems occur at various stages of development and with varying intensity. The development of the nervous system is the fastest, whereas the reproductive system matures most slowly.

Children's physical capacity is influenced by properly conducted training. Physical activity should be encouraged regardless of age and not only to improve capacity, but also to ensure that body mass and the amount of fat are at the correct reference level [10]. However, it is necessary to make certain that physical activity is appropriately matched to children's motor abilities and physical capacity. This is a form of prevention against the risk of injury and excessive burden to the motor organ [8].

Increased blood supply to muscles during physical exercise, their overload due to the influence of physical activity and lack of post-exercise restitution affect changes in the thermogenesis of the body. By measuring the surface body temperature of athletes with back pain, Badza [11] was able to determine the exact location and advancement of dysfunction. As a result, the athletes received special local cooling treatment as part of the physiotherapeutic procedure.

In this research, differences in surface body temperatures were observed between boys and girls in the individual measurement fields. The highest average temperature values were measured in the shoulder belt and the trunk area. Lower values were recorded in the lowerlimb area. A similar distribution of temperatures was described by Chudecka and Lubkowska [13], who examined a group of healthy men and women aged 20-23. The differences in the anatomical structure of the lower limbs and torso can be the reason for variation in the distribution of surface body temperatures.

The torso contains organs that constitute the main source of heat in humans, which is additionally distributed through large blood vessels. Heat generated in lower-limb muscles is distributed through small capillaries [14]. The fact that the surface of the lower limbs is larger in relation to their volume results in easier heat transfer, which may be the reason for the observed differences in the distribution of surface body temperatures. Another element that could explain the differences in the obtained measurements is the amount of adipose tissue. Because it is a poor conductor of heat, lower body temperatures are recorded in areas of its high accumulation [15]. Similar conclusions were drawn by Sobiech et al. [16], whose research showed that the temperature of body areas with a higher content of adipose tissue is lower.

The energy generated by the human body (about 60\%) is released as infrared radiation (IR), which makes it possible to measure the distribution of temperatures on human skin. Thermal energy emitted from the core of the body is mainly supplied by blood flow. Heat transfer also occurs on the skin surface through sweating and evaporation, convection and conduction. All these processes that are performed to maintain thermal homeostasis are controlled by the hypothalamus - it is responsible for controlling blood flow and monitoring thermoregulatory mechanisms. If the human thermostat is not stimulated, thermoregulation processes result from a specific pattern. Heat transfer is closely related to the temperature gradient between the body surface and the environment. At rest, thermal energy is transported to skeletal muscles from the core of the body. The proximity of large body cavities and the internal organs inside them affects the surface temperature distribution; hence, the thermal map of the body can present the distribution of the warmest regions in the trunk, corpus and then upper and lower limbs [15, 20].

This research has shown a statistically significant decrease in the surface body temperature in the area of the trunk, upper limbs and lower limbs after general physical training in both girls and boys. Similar results were obtained by Chudecka and Lubkowska, whose research 
was conducted on a group of volleyball players. The players did a 90-min workout. Thermographic measurements were taken before, immediately after and $10 \mathrm{~min}$ after the completion of the workout. The measurements taken immediately after the exercises showed a statistically significant decrease in temperature. The efficiency of the athletes' thermoregulation system enabled them to continue physical effort without increasing their core body temperature [17]. Systematic training improves physical capacity. Thanks to this, during physical exertion there is a smaller increase in core temperature, whereas the amount of sweat excretion increases. These processes decrease the temperatures recorded on the body surface [18].

Korman et al. [19] observed in their analysis that body temperatures in a group of Polish runners decreased as a response to physical activity. This change was noticed immediately after the warm-up, and measurements taken after the main part of the exercise showed that the temperatures remained at a very similar level. Such a rapid response of the body to physical effort indicates the proper functioning of the thermoregulation system. Research by Kasprzyk et al. [20], which analyzed the efficiency of thermoregulatory processes in cyclists, demonstrated an analogous reaction of the body thermostat in response to physical activity in the form of cycloergometer exercise.

Having analyzed the thermoregulatory response of the human body to cycling endurance test, Cholewka et al. [21] demonstrated a decrease in body surface temperature at the beginning of the test. It is connected with the movement of blood in the cutaneous vasculature to the muscles, where the work is done and oxygen is needed. In fact, blood circulation is very important in the transport of body heat. However, the exchange of heat on the surface of the body will not take place immediately because of the time needed for microcirculation changes in the capillaries, which are responsible for the temperature of the skin. These processes are dependent on each other. Heat transport takes time, which is a consequence of body core thermoregulation inertia. The mechanism of heat exchange is activated when information about body and blood temperature change is delivered to the hypothalamus.

The literature on the subject contains works that emphasize differences in the process of thermoregulation between children and adults during exercise. Falk and Dotan [7] highlight metabolic, morphological and cardiovascular differences and above all less effective perspiration as the biggest physiological discrepancy between the two groups. Due to the above, the amount of sweat produced in children is small [22]. The results of research carried out by Bar-Or et al. [23] emphasize that the reduced production of sweat in children compared to adults is more pronounced in boys than in girls. When analyzing the results of the research described in this paper, lower body temperatures in the torso and upper-limb areas were observed in girls directly after the physical activity. This may indicate that the sweating and cooling process is more developed in girls than in boys.

By analyzing surface body temperature distribution after post-workout restitution in boys and girls, it was possible to determine that temperature values increased in both groups, although there were intergroup differences. In Test 3, an increase in the initial temperatures was observed in all the measured areas in girls, whereas in boys this parameter increased only in the area of the lower limbs. It should be noted that thermographic measurements in Test 2 showed a greater reduction in temperature in girls than in boys, and yet after $15 \mathrm{~min}$ of restitution the girls' body surface temperatures exceeded the temperatures measured in Test 1. The obtained results may suggest that the thermoregulation system in 7-year-old girls included in this research functioned more efficiently than in boys.

The results of this research are similar to the conclusions of Cholewka et al. who, by analyzing the surface body temperatures of cyclists, showed a similar relationship in the athletes' thermal map gradient during the training unit and in the restitution process. The authors observed temperature distributions similar to the results obtained in this research and also demonstrated the usefulness of thermal imaging as a diagnostic tool in sport and as a useful method in assessing sports performance [21].

Hunold et al. [24] also studied how surface body temperatures change in response to physical effort. The research subjects underwent cycloergometer exercise at $100 \mathrm{~W}$. Curves of the thighs and forearms were taken before, during $(5 \mathrm{~min})$ and after $10 \mathrm{~min}$ of exercise. The initial temperature was $31.9{ }^{\circ} \mathrm{C}$, and after 5 min a regression of $0.4{ }^{\circ} \mathrm{C}$ was recorded. The body temperature after 10 min was greater than that at the beginning $\left(32.4{ }^{\circ} \mathrm{C}\right)$. The researchers explained the increase in temperature in the third measurement as the beginning of the widening of blood vessels, i.e., vasodilatation.

In order to observe the efficiency of thermoregulatory processes both while performing physical activity and during restitution, Merla et al. [25] studied a group of 15 runners. The subjects ran on a treadmill until each of them achieved individually determined maximum heart rate. As it was the case in Korman's study, a reduction of surface body temperatures already occurred after the warm-up. The obtained values were $3-5{ }^{\circ} \mathrm{C}$ lower than those at the beginning of the test. During restitution, an increase in body temperatures was measured in all the studied areas (forearm, torso, thighs), but this process was observed first in peripheral parts.

Due to their noninvasiveness and ease of conducting, thermographic tests are becoming increasingly often used to assess the efficiency of thermoregulation processes and 
consequently to assess the physical capacity of human beings.

This research was conducted in order to evaluate thermoregulation processes in early school-age girls and boys as a way of monitoring the load of training or therapeutic exercise in children and preventing musculoskeletal injuries.

\section{Conclusions}

1. Thermographic tests showed that the distribution of body surface temperature differed in boys and girls depending on the measurement field. The thermal map of the body of the examined children presented a similar gradient of the tested parameter.

2. After general physical exercise, a statistically significant decrease in temperature in all the measurement fields was recorded in both groups, although it was higher in the group of girls.

3. The results of this thermographic study demonstrated a greater efficiency of thermoregulation processes in girls, whose body temperatures changed faster in response to physical effort. During post-exercise restitution in girls, it was observed that temperature values returned to and exceeded the baseline values in all the measurement areas.

Open Access This article is distributed under the terms of the Creative Commons Attribution 4.0 International License (http://creative commons.org/licenses/by/4.0/), which permits unrestricted use, distribution, and reproduction in any medium, provided you give appropriate credit to the original author(s) and the source, provide a link to the Creative Commons license, and indicate if changes were made.

\section{References}

1. Dębiec-Bạk A, Pawik $€$, Skrzek A. Monitoring the training process in thermovision studies. In: Podbielska H, Skrzek A, editors. Biomedical applications of thermovision. Wrocław: Wroclaw University of Technology Publishing House; 2014.

2. Falk B, Dotan R. Temperature regulation and elite young athletes. Elit Young Athl. 2010;56:126-49.

3. Székely M, Garai J. Thermoregulation and age. Handb Clin Neurol. 2018;156:377-95.

4. Ganong WF. Central regulation of visceral activities. Physiology. Warsaw: Medical Publisher PZWL; 2009.

5. Davis JK, Baker LB, Barnes K, Ungaro C, Stofan J. Thermoregulation, fluid balance, and sweat losses in American football players. Sport Med. 2016;46:1391-405.

6. Dębiec-Bạk A, Skrzek A. Comparison of the body surface temperature distribution of men and women using thermovision. Acta Bio Opt Inform Med. 2012;18(1):25-30.

7. Falk B, Dotan R. Children's thermoregulation during exercise in the heat-a revisit. Appl Physiol Nutr Metab. 2008;33:420-7.
8. Sinclair WH, Crowe MJ, Spinks WL, Leicht AS. Pre-pubertal children and exercise in hot and humid environments: a brief review. J Sport Sci Med. 2007;6:385-92.

9. Pham DD, Lee JH, Park ES, Baek HS, Kim GY, Lee YB, Ku BC, Kim JY, Leem $\mathrm{CH}$. Thermoregulatory responses to graded exercise differ among Sasang types. Evidence Based Complement Altern Med. 2015;2015:1-10.

10. Yeargin SW, Casa DJ, Judelson DA, McDermott BP, Ganio MS, Lee EC, Lopez RM, Stearns RL, Anderson JM, Armstrong LE. Thermoregulatory responses and hydration practices in heat-acclimatized adolescents during preseason high school football. J Athl Train. 2010;45:136-46.

11. Badza V, Jovancević V, Fratrić F, Roglić G, Sudarov N. Possibilities of thermovision application in sport and sport rehabilitation. Vojnosanit Pregl. 2012;69(10):904-7.

12. Luis HL, Gomes S, Carneiro-Júnior MA, Carlos JB, Marins S. Thermoregulatory responses of children exercising in a hot environment. Rev Paul Pediatr. 2013;31(1):104-10.

13. Chudecka M, Lubkowska A. Thermal maps of young women and men. Infrared Phys Technol. 2015;69:81-7.

14. Dębiec-Bąk A, Skrzek A, Jonak A. Differentiation of surface temperature of the body under the influence of various stimuli in thermovision studies. Acta Bio Opt Inform Med. 2009;15(4):322-7.

15. Skrzek A, Dębiec-Bąk A, Gruszka K, Sobiech KA. Analysis of variability of body surface temperature distribution in thermovision studies. Wrocław: In Biomedical applications of thermovision. Wrocław University of Technology Publishing House; 2014.

16. Sobiech K, Skrzek A, Dębiec-Bąk A, Gruszka K, Socha M, Jonak W. Dynamics of body temperature changes in women under the influence of systemic cryotherapy. Acta Bio Opt Inform Med. 2009;15(4):315-8.

17. Chudecka M, Lubkowska A. The use of thermal imaging to evaluate body temperature changes of athletes during training and a study on the impact of physiological and morphological factors on skin temperature. Hum Mov. 2012;13(1):33-9.

18. Chudecka M, Lubkowska A. Thermovision assessment of temperature changes of the basketball body surface after training. Acta Bio Opt Inform Med. 2011;17(4):271-4.

19. Korman P, Straburzyńska-Lupa A, Kusy K, Kantanista A, Zieliński J. Changes in body surface temperature during speed endurance work-out in highly-trained male sprinters. Infrared Phys Technol. 2016;78:209-13.

20. Kasprzyk T, Cholewka A, Kucewicz M, Sieroń K, SilleroQuintana M, Morawiec T, Stanek A. A quantitative thermal analysis of cyclists' thermo-active base layers. J Therm Anal Calorim. 2019;136:1689-99.

21. Cholewka A, Kasprzyk T, Stanek A, Sieroń-Stołtny K, Drzazga Z. May thermal imaging be useful in cyclist endurance tests? J Therm Anal Calorim. 2016;123(3):1973-9.

22. Janiec I, Werner B. Treadmill tests in children. Pediatr Pol. 2012;87(1):58-64.

23. Bar-Or O. Thermoregulation in females from a life span perspective. In: Lamb DR, Clarkson PM, editors. Exercise and the female: a life span approach. Traverse City: Cooper Publishing Group; 1996.

24. Hunold S, Mietzsch E, Werner J. Thermographic studies on patterns of skin temperature after exercise. Eur J Appl Physiol. 1992;65:550-4.

25. Merla A, Mattei PA, Di Donato L, Romani GL. Thermal imaging of cutaneous temperature modifications in runners during graded exercise. Ann Biomed Eng. 2010;38(1):158-63.

Publisher's Note Springer Nature remains neutral with regard to jurisdictional claims in published maps and institutional affiliations. 